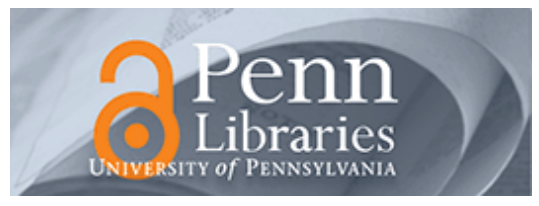

University of Pennsylvania

ScholarlyCommons

\title{
The "Difficult" Patient Reconceived: An Expanded Moral Mandate for Clinical Ethics
}

Autumn Fiester

University of Pennsylvania, fiester@mail.med.upenn.edu

Follow this and additional works at: https://repository.upenn.edu/bioethics_papers

Part of the Bioethics and Medical Ethics Commons

\section{Recommended Citation}

Fiester, A. (2012). The "Difficult" Patient Reconceived: An Expanded Moral Mandate for Clinical Ethics. The American Journal of Bioethics, 12 (5), 2-7. http://dx.doi.org/10.1080/15265161.2012.665135

This is an Accepted Manuscript of an article published by Taylor \& Francis in the American Journal of Bioethics in January 2012, available online: http://wwww.tandfonline.com/doi/10.1080/15265161.2012.665135.

This paper is posted at ScholarlyCommons. https://repository.upenn.edu/bioethics_papers/82

For more information, please contact repository@pobox.upenn.edu. 


\title{
The "Difficult" Patient Reconceived: An Expanded Moral Mandate for Clinical Ethics
}

\begin{abstract}
Between $15 \%-60 \%$ of patients are considered "difficult" by their treating physicians. Patient psychiatric pathology is the conventional explanation for why patients are deemed "difficult." But the prevalence of the problem suggests the possibility of a less pathological cause. I argue that the phenomenon can be better explained as responses to problematic interactions related to healthcare delivery. If there are grounds to reconceive the "difficult" patient as reacting to the perception of ill treatment, then there is an ethical obligation to address this perception of harm. Resolution of such conflicts currently lies with the provider and patient. But the ethical stakes place these conflicts into the province of the ethics consult service. As the resource for addressing ethical dilemmas, there is a moral mandate to offer assistance in the resolution of these ethically charged conflicts that is no less pressing than the more familiar terrain of clinical ethics consultation.
\end{abstract}

\section{Keywords}

bioethics, clinical ethics, medical ethics

\section{Disciplines}

Bioethics and Medical Ethics | Medicine and Health Sciences

\section{Comments}

This is an Accepted Manuscript of an article published by Taylor \& Francis in the American Journal of Bioethics in January 2012, available online: http://wwww.tandfonline.com/doi/10.1080/

15265161.2012.665135. 


\title{
PLEASE DO NOT CITE WITHOUT PERMISSION OF THE AUTHOR
}

\begin{abstract}
Between 15\%-60\% of patients are considered "difficult" by their treating physicians. Patient psychiatric pathology is the conventional explanation for why patients are deemed "difficult." But the prevalence of the problem suggests the possibility of a less pathological cause. I argue that the phenomenon can be better explained as responses to problematic interactions related to healthcare delivery. If there are grounds to reconceive the "difficult" patient as reacting to the perception of ill treatment, then there is an ethical obligation to address this perception of harm. Resolution of such conflicts currently lies with the provider and patient. But the ethical stakes place these conflicts into the province of the ethics consult service. As the resource for addressing ethical dilemmas, there is a moral mandate to offer assistance in the resolution of these ethically charged conflicts that is no less pressing than the more familiar terrain of clinical ethics consultation.
\end{abstract}




\section{PLEASE DO NOT CITE WITHOUT PERMISSION OF THE AUTHOR}

The "Difficult" Patient Reconceived:

An Expanded Moral Mandate for Clinical Ethics

Between 15\%-60\% of patients are considered "difficult" by their treating physicians (Hahn 1994; Jackson and Kroenke 1999; Hahn 2001). Even at the lower end of those estimates, the implication is that a significant portion of doctor-patient relationships are fraught with conflict, negative feelings, and unsatisfying interactions. There is no shortage of literature highlighting the harmful consequence to both physician and patient of a dysfunctional treating relationship (Lin 1999; Steinmetz 2001; Wasan 2005; Miksanek 2008), so the moral imperative to resolve such conflicts is clear. But the remedy, of course, depends on the cause. The conventional explanation for these conflicts lays the blame squarely at the feet of the patient, typically via mental disorders or maladaptive personality traits, and the specter of flawed moral character lurks as well. But the prevalence of the problem either serves as a psychological and moral indictment for up to $60 \%$ of our citizenry, or its pervasiveness suggests the possibility of a less pathological cause. In fact, I argue that the behaviors that saddle a patient with the label "difficult" can better be explained as responses to problematic interactions or negative experiences related to the delivery of medical care. If there are grounds to reconceive the "difficult" patient as someone reacting to the perception of ill treatment in the clinic-someone who feels morally wronged - then there is an ethical obligation to address this perception of harm. 


\section{PLEASE DO NOT CITE WITHOUT PERMISSION OF THE AUTHOR}

Resolution of such conflicts currently lies solely in the dyad of provider and patient. But the ethical stakes, I argue, place this species of conflict into the province of the ethics consult service (ECS). As the resource for addressing ethical dilemmas that occur at the bedside or clinic, there is a moral mandate to offer assistance in the resolution of this pervasive type of ethically charged conflict that is no less pressing or consequential than the more familiar terrain of clinical ethics consultation.

\section{The Conventional View of the "Difficult" Patient}

Research on the "difficult" patient generally defines the problem exclusively from the physician's perspective (Kahn 2009; Haas 205; Gerrard and Riddell 1988; Lin 1999; Steinmetz 2001; Miksanek 2008). "Difficult" patients are typically described as "those who raise negative feelings within the clinician," presumably due to behaviors deemed "inappropriate" in a treatment setting (Wasan 2005). The clinician's experience of frustration, anxiety, guilt, or dislike in interactions with the patient frames the research that explores the causal explanation of the dysfunctional dynamic. The conclusion reached by most studies is that a set of patientcentered problems or flaws accounts for the inappropriate behavior. The most commonly attributed cause of the "difficult" patient is the presence of a psychiatric disorder. Concludes one study, "The difficult or frustrating patient...often has unrecognized psychiatric problems" (Haas et al 2005). Others concur (Lin et al 1991; Hahn 1996). The candidates for such psychiatric diagnoses range from depression and anxiety to "comorbid psychopathology, hostility, suicidality, aberrant drug behavior, and chronic noncompliance” (Wasan 2005). 


\section{PLEASE DO NOT CITE WITHOUT PERMISSION OF THE AUTHOR}

What seems to go unnoticed in these studies is that some of what is couched as mental illness falls well inside the range of "normal" for individuals faced with significant life-stressors such as either illness or the perception of ill treatment. Hostility, anger, depression, anxiety and even noncompliance are common reactions to difficult circumstances, even among the psychologically healthy and typically well-adjusted. Even if we grant that some patients who exhibit behaviors that get them labeled "difficult" have a diagnosable psychiatric disorder, there will be others who exhibit these same behaviors who do not: though there may be a correlation in some patients of psychiatric diagnosis and "difficult" behaviors, this does not demonstrate causation. In fact, even among those patients who have both a psychiatric diagnosis and are perceived as "difficult," it is not clear that the negative behaviors are caused by the patient's psychiatric condition.

A closer look at one of the studies that confidently claims that "significant psychopathologic disorders" (Hahn 2001) is the root cause of the "difficult" patient reveals how spurious that conclusion really is. Hahn's own study finds two other significant factors that correlate strongly with physician-perceptions of “'hateful,' 'heartsink,' 'problem,' or 'difficult' patients" (Hahn 2001). First, 90\% of the patients described as "difficult" were found to have an "abrasive personality style," which is practically a tautological conclusion: the meek and mild wouldn't be forceful enough to earn the title "difficult," so it is definitionally true that temperament plays a large role in landing a patient in this category. Second, the most significant predictor of being labeled "difficult" - and one that could not be explained away by association with psychopathology - was having multiple symptoms, five in particular: "stomach pain, fainting, sleep problems, loose stools/diarrhea, and palpitations" (Hahn 2001). These patients 


\section{PLEASE DO NOT CITE WITHOUT PERMISSION OF THE AUTHOR}

were reported by physicians as being both "time consuming" and "manipulative," and they garnered high levels of physician-frustration. Though Hahn takes great pains to convince the reader that patients with psychopathologies have a predilection for psychosomatic complaints and that somatoform disorders might thus account for the correlation between "difficult" and "multiple symptoms," he admits that physicians are "frustrated by the symptoms' 'vagueness' and their own inability to make a diagnosis" (Hahn 2001). In other words, a physician may label a patient "difficult" because of her own inability to effectively diagnose or treat the problem, or because of a patient's reaction to this failure.

All told, then, the foregoing explanations for the "difficult" patient are partial at best and specious at worst.

\section{The "Difficult" Patient Reconceived}

The studies designed to detect the causes of the problematic patient expend almost no attention defining the set of patient-behaviors that provoke the label "difficult." Although one author defends this lack of precision by claiming that it is "intuitively understood" (Hahn 2001), it turns out that there is a wide range of behaviors falling under this rubric in the literature, many of which do not even seem inappropriate, let alone pathological. In the laundry list of one study, the "difficult" patient includes: "patients who make repeated visits without apparent medical benefit, patients who do not seem to want to get well, patients who engage in power struggles, and patients who focus on issues seemingly unrelated to medical care" (Haas 2005). In contrast to this relatively benign list, a different study identifies the set as: "[i]nvalidating, demanding, disruptive, attention-seeking, annoying, and manipulative behavior" (Knesper 2007). To make 


\section{PLEASE DO NOT CITE WITHOUT PERMISSION OF THE AUTHOR}

the case that we need to reconceive the "difficult" patient, I want to focus on the worst of what might invite this label, namely, behaviors that include: raising one's voice or shouting, using foul language, making accusatory remarks or insulting comments, making racial or ethnic slurs, or using sexist, homophobic, racist, or anti-Semitic epithets. If these incontrovertibly inappropriate behaviors lend themselves to a more compelling explanation than patient-pathology, then the arguably more benign set surely will. To make the argument, then, that we have misdiagnosed the underlying cause of the "difficult" patient, let's look at the following case of Fred:

Case

Fred is a 17-year-old man with an incomplete C-4 injury to his spinal cord as the result of a gunshot wound. He is currently unable to move his arms or legs, though he does have sensation in his lower extremities. Before his injury, Fred attended school intermittently and was on probation for heroin possession. Fred was admitted to an in-patient rehabilitation unit after two weeks in acute care. His mother is unable to visit during the week because of her work schedule and the patient's only other living relative is an elderly grandmother who is homebound. Since he has come to the rehab hospital, Fred has been verbally abusive to staff, frequently using racial slurs. His cursing, often loud, distresses the other patients, as well as the physicians and other staff. Fred often complains of pain and screams loudly when moved, though his physicians insist he is on the highest dose of narcotics that they feel comfortable prescribing. Because of Fred's language and derogatory comments, both physicians and nurses are starting to refuse to work with him.

Fred is difficult.

What makes Fred an ideal patient to discuss in this context is that he obviously has an "abrasive personality style," indisputably has multiple symptoms, some of which are being presumed to be exaggerated or imagined, and likely has at least one psychiatric diagnosis. And yet...we could put ourselves in Fred's shoes and envision myriad interactions that he might experience on a daily basis at this rehab hospital that would seriously test our equanimity and self-possession, though we may have none of the hypothesized causes for being difficult. 


\section{PLEASE DO NOT CITE WITHOUT PERMISSION OF THE AUTHOR}

Consider the treatment, situations and dynamics that would provoke anyone's ire as a patient. How often has Fred felt patronized, dismissed, demeaned, or humiliated? How many needless indignities has he been subjected to? Does he feel powerless and emasculated, and, if so, from the injury or the treatment they are giving for it? Does he feel heard, validated, and respected? Does he believe that they are treating him as well as they treat all other patients, or does he sincerely believe that their view of him is prejudiced by his past truancy and heroin use? Does he feel victim to being branded "drug-seeking," "gang member," "high school drop-out," or "junkie"? Does he believe that the clinical team really cares about him? Do they?

The key to Fred's escalating bad behavior lies in the answers to the question: does Fred feels mistreated or wronged? Persons who feel indignation, resentment, or offense are susceptible to manifesting their moral grievance in counterproductive ways. Only the most selfcontrolled consistently work through moral offense by calm, rational, productive means. Fred's behavior should be first and foremost understood as a reaction to a therapeutic situation that is malfunctioning for him, failing to meet his needs, and perhaps undermining his sense of self and self-esteem. But you might object: which came first, his bad behavior or his perception that he is being treated badly? Let's assume that he treated the staff badly from the moment of his in-take, motivated not by a loss of faith in the medical establishment from his stay at the acute-care hospital, but sourced solely in the horrific situation he finds himself in: he was merely angry at fate, God, the person who shot him, his family - who knows - but there was no culpability on the part of any clinical provider. Let's grant all of that. What reactions did he get at the rehab hospital to his understandable anger and frustration? What stereotypes or bias lie underneath the attitudes or perceptions of his current caregivers? What sources of support did they offer him? 


\section{PLEASE DO NOT CITE WITHOUT PERMISSION OF THE AUTHOR}

How did they reassure him that his mental, spiritual, emotional, and physical well-being would be safeguarded with them?

Lending credence to this reconceived view of the "difficult" patient is an older nursing study that looked at the perspectives of patients deemed "difficult" by their clinical team. The study participants claimed that if they were given more respect and decision-making power, their potent feelings of anger would be significantly reduced (Breeze and Repper 1998). Another

study found that causal explanations for the behavior of the "difficult" patient differed markedly between physician and patient (Lin 1991). Tellingly, physicians who scored lower on scales measuring empathy were more likely to perceive their patients as "difficult" than those who scored higher (Jackson and Kroenke 1999). The moral of this study, then, is that the behaviors being exhibited by patients are less objectively "difficult" and more vulnerable to the "eye of the beholder" problem that may over-state or exacerbate those negative behaviors.

The conventional view that locates the source of patient-provider conflict in the patient's mental or physical pathologies is not only weak as an explanatory model, but ethically irresponsible for the way it undermines our resolve to explore more nuanced causal dynamics and redress them. The reconceived view of the "difficult" patient calls for that exact reexamination, viewing the fractured patient-provider relationship not only as amendable to repair, but as demanding that level of moral attention.

\section{The Ethical Obligations to the "Difficult" Patient}

Re-framing the "difficult" patient as someone who perceives himself as wronged in the medical encounter - perceives being treated unfairly, disrespectfully, dismissively, 


\section{PLEASE DO NOT CITE WITHOUT PERMISSION OF THE AUTHOR}

condescendingly, or offensively - generates an ethical duty to address, validate, repair, or assist in making amends. And those obligations to assist are binding whether the ethical harm is perceived or real. In other words, whether there is any true culpability on either side misses the point: if my behavior towards you is reactive, the solution for altering it is to change my perceptions. Take as an example: if a patient's perceptions shift from feeling dismissed to feeling validated, the original intentions, dynamics, or actions on the part of the provider are not relevant. The provider may have had the very best of intentions, and the perception of the provider's being dismissive could have been pure misunderstanding. But what matters in resolving "difficult" behavior is that a new understanding of mutual respect has been forged, and that new understanding will translate into transformed conduct on the part of the patient.

Lest this analysis itself seems condescending to the "difficult" patient, consider the case of Susan.

\section{Case}

Susan is the mother of an 8-year-old daughter, Emily, who has come to a children's hospital for a possible fracture of a growth plate in her ankle. Emily's injury is a week old, but it took that long to get an appointment with the pediatric orthopedic surgeon and could not be treated by her general pediatrician. Emily has been in significant pain all week. Susan and Emily arrive on time for their 1:00 appointment, where they are shown into a small, sparse exam room with no toys or books. After an hour of waiting, Susan goes to speak with an unfriendly receptionist who tells her she has no idea how much longer it will be. Another hour goes by, and Emily is in pain, bored, cranky, and hungry. When the orthopedic surgeon finally arrives at 3:30, he is brusque, offers no apology for the extensive wait, and starts to complain that his busy day has allowed him time only to eat two Powerbars. Susan begins to yell loudly at the clinician.

The case of Susan is instructive because there is clear culpability on the care-delivery side. At the very least, there is a systems-level problem in both appointment scheduling and adequate infrastructure for pediatric patients; but also the physician seems to bear some responsibility for 


\section{PLEASE DO NOT CITE WITHOUT PERMISSION OF THE AUTHOR}

Susan's outburst by his failure to acknowledge the institutional issues, his brusque bedside manner, and the mention of his own needs before addressing Emily's. Susan has compelling grounds for taking offense: this is no mere misunderstanding. But the approach to remedying Susan's negative reaction - i.e., the means to resolve or alter her "difficult" behavior - does not differ or depend on the moral fact-pattern of the case. She is offended and feels wronged on behalf of her daughter, and when she feels her concerns have been heard, validated and addressed, she will surely stop yelling.

The moral salve called for in such cases is the basic set of conflict-resolution techniques, and this is not lost on the authors of research about the "difficult" patient. One author after another advises an approach to resolving the problems in the doctor-patient relationship through a process either implicitly or explicitly identified as mediation and negotiation. For example, in the piece, "My Favorite Tips for Engaging the Difficult Patient on Consultation-Liaison Psychiatry Services," the author is quite upfront about borrowing his solutions from the Harvard Negotiation Project (Knesper 2007). Knesper suggests, first, a strategy of "mediation and developing the third story," a key concept from a well-known book by Harvard Negotiation Project instructors of developing a version of the events that both disputing parties can agree on (Stone, Patton, and Heen 1999); and, second, a process of "negotiating, concession making, and control sharing" (Knesper 2007), a classic next-step in the mediation method. In a recent NEJM piece on dealing with the "difficult" patient, the author advocates gleaning insights from conflictresolution methodology, for example, arguing, "Successful negotiation begins with some basic understanding of the other side's position" (Kahn 2009). Others writing on the "difficult" patient allude to mediation methods, though not by name (Bellet 1994; Haas 2005), and one author 


\section{PLEASE DO NOT CITE WITHOUT PERMISSION OF THE AUTHOR}

generates a didactic mnemonic that could have been plucked straight from classic negotiation texts:

"Five A's for Dealing with Hostile Patients"

1. Acknowledge the problem.

2. Allow the patient to vent uninterrupted in a private place.

3. Agree on what the problem is.

4. Affirm what can be done.

5. Assure follow-through (Wasan 2005).

The recommendations and guidance offered by these authors are intended for the physicians directly involved in conflicts with their patients. They are meant to help the clinician cope more effectively with patients they view as "'hateful,' 'heartsink,' 'problem,' or 'difficult." But while a mediation skill set is very handy to have, and may indeed forestall problems or even rectify a doctor-patient relationship gone bad, it is asking a lot of a stakeholder in a conflict to also be that conflict's mediator. In fact, although the authors cited above accurately represent the relevant mediation techniques, they fail to grasp one of the fundamental principles of mediation: it is a process conducted by a neutral third party. Physicians embroiled in a doctor-patient conflict are dealing with negative feelings of anger, frustration, anxiety, or guilt - after all, the very definition of the "difficult" patient is someone who engenders those very feelings. Physicians in these conflicts are partisans, and as such, it is not easy for them to bracket those negative feelings in order to conduct a conversation that is impartial or lacks an intrinsic bias. If they can, they deserve a great deal of credit. But having that ability or skill set in such situations should not be an expectation. Think about the suggestion by Knespser of creating a "third story." Write the Harvard Negotiation Project authors, “The Third Story is one an impartial observer, such as a mediator, would tell; it's a version of events both sides can agree on" (Stone, 


\section{PLEASE DO NOT CITE WITHOUT PERMISSION OF THE AUTHOR}

Patton, and Heen 1999). Anything short of being able to generate that third story undercuts the usefulness and value of what a mediation process could bring to these conflicts. Physicians not able to achieve that in a conflictual interaction with a patient need a resource external to the dyad of doctor and patient.

\section{The "Difficult" Patient and the Role of the Ethics Consultation Service}

The institution in American medicine charged with both addressing ethics-infused conflicts and possessing the skill set to mediate them is the ethics consultation service (ECS). Required by The Joint Commission, each hospital must have "a process that allows staff, patients, and families to address ethical issues" (TJC 2010), and this is operationalized in most institutions through an ethics committee and/or clinical ethicist. It is the ECS that should provide the resource for resolving the ethically charged conflicts between the "difficult" patient and his or her clinical team that have not been able to be successfully managed within those relationships.

That this species of conflict legitimately falls within the sphere of the ECS can be clearly seen in the self-described mission of those ethics bodies. In a highly regarded national study of ECSs, participants were asked about the primary goals of their ethics consultation service (Fox et al 2007). Assisting in the repair of the relationships between patients deemed "difficult" and the providers reluctant to continue working with them meets many of the most frequently cited goals of ECSs in that study: $77 \%$ of ECSs viewed their charge as "resolving real or imagined conflicts;" $75 \%$ as "changing patient care to improve quality;" 68\% as "increasing patient/family satisfaction;" and, 50\% as "meeting a perceived need of the staff” (Fox et al 2007). Not only 


\section{PLEASE DO NOT CITE WITHOUT PERMISSION OF THE AUTHOR}

does addressing these conflicts fit well within those explicit goals, I am arguing the stronger point that ECSs actually shirk their duty by failing to recognize this obligation as being part of their self-identified mandate. Without a serious response to the real or imagined ethical offenses and injuries involved in these conflicts, patient care will necessarily remain sub-standard in the patients' perspective, therefore, they couldn't possibly feel satisfied with the care they have received; and correspondingly, the needs of the staff will also go unmet.

If it is granted that conflicts involving the "difficult" patient arguably fall under the purview of the ECS, do ECSs possess the skill set to navigate them? There are two separate issues embedded in this important question: first, what skills should an ECS have?; and, second, what skills do most ECSs actually possess? Taking the latter question first, it is well-known that ECSs in general have little training (Fox et al 2007), and a task force created by the national bioethics organization - the American Society of Bioethics and Humanities - has been formed to address this pervasive problem (CECA 2010). But although this may appear as a glib dodge to a very worrisome problem, my answer to the second question is that ECSs are currently no less qualified to navigate this type of ethics conflict than any other.

The former question - what skills ought an ECS have? - has a more straightforward answer, and these skills make them the ideal body to resolve conflicts between patients labeled "difficult" and the providers they work with. Universally, the various task forces charged with determining this key skill set deem mediation techniques - from facilitation to other modes of conflict resolution - as essential process skills. For example, the National Working Group for the Clinical Ethics Credentialing Project lays out the "Fundamental Elements of Clinical Ethics Consultation," writing "Clinical ethics consultation is an intervention in which a trained clinical 


\section{PLEASE DO NOT CITE WITHOUT PERMISSION OF THE AUTHOR}

ethics professional: ...employs expert discussion of bioethical principles, practices, and norms and uses reason, facilitation, negotiation, or mediation to seek a common judgment regarding a plan of care going forward" (Dubler et al 2009). Similarly, the national bioethics organization (ASBH) recently revisited, and largely reaffirmed, its earlier report (Aulisio et al 2000) on the necessary qualifications of ECSs, what are known as the "Core Competencies" (ASBH 2011). They write, "We believe an ethics facilitation approach is most appropriate for HCEC [healthcare ethics consultation]," and they list, as an indispensable skill of facilitation, the ability to "apply mediation or other conflict resolution techniques" (ASBH 2011). Further clarifying, they write, "Bioethics mediation is a well-tested conflict resolution technique. It combines the clinical substance and perspective of clinical ethics consultation with the tools of the mediation process, using the techniques of mediation and dispute resolution to promote a principled resolution, compatible with the principles of bioethics and the legal rights of patients and families (ASBH 2011; referencing Dubler and Liebman 2011). Others have made similar arguments on the essential role mediation plays in resolving clinical ethics disputes (Dubler and Liebman 2011; Caplan and Bergman 2009; Fiester 2007a; 2007b; 2011).

If adequately trained in the compulsory competencies outlined by various clinical ethics working groups, the ECS is the ideal resource to provide assistance in mediating this class of ethics-related conflicts when they have proven intractable to the efforts of the treating providers. This work is not only commensurate with the mission and function of the ECS, but the resolution of these conflicts is universally recognized as requiring a very particular skill set that is rare among clinical providers and obligatory for members of ECSs. Although the "difficult" patient and the dysfunctional patient-provider relationship that is its sequelae are currently not explicitly 


\section{PLEASE DO NOT CITE WITHOUT PERMISSION OF THE AUTHOR}

named as cause for calling an ethics consult, this problematic dynamic likely undergirds the vast majority of the consults requested. Explicitly identifying this type of conflict as a legitimate reason for prompting a consult would enable the resources of the ECS to be initiated early in the conflict, before it has irreparable consequences to the patient-provider relationship or a detrimental impact on provider morale. We need to expand the moral mandate of the ECS to include addressing the conflicts between the "difficult" patient and the providers who treat them. 
Autumn Fiester, PhD

Department of Medical Ethics and Health Policy

Perelman School of Medician at the University of Pennsylvania

\section{PLEASE DO NOT CITE WITHOUT PERMISSION OF THE AUTHOR}

\section{REFERENCES}

2011 Joint Commission standards for acute care hospitals, revised December, 2010. http://www.cihq-hacp.org/images/pdf/2011_TJC_Acute_Care_Standards_-_Rev12.10.pdf. Accessed October 10, 2011.

American Society for Bioethics and Humanities. 2011. Core competencies for healthcare ethics consultation, $2^{\text {nd }}$ edition. Glenview, IL: ASBH.

Aulisio, M. P, R. M. Arnold, and S. J. Youngner . 2000. A position paper from the Society for Health and Human Values-Society for Bioethics Consultation Task Force on Standards for Bioethics Consultation. Health care ethics consultation: nature, goals, and competencies. Annals of Internal Medicine 133(1):59-69.

Bellet, P. 1994. How should physicians approach the problems of their patients? Pediatrics 94: 928-931.

Breeze, J.A. and J.Repper. 1998. Struggling for control: the care of experiences of "difficult" patients in mental health services. Journal of Advanced Nursing 28: 130-1311.

Caplan, A., and E. Bergman. 2007. Beyond Schiavo. Journal of Clinical Ethics 18(4): 340-345.

Clinical Ethics Consultation Affairs Committee. 2010. CECA report to the Board of Directors, ASBH on Certification, Accreditation, and credentializing of Clinical Ethics Consultants. http://www.asbh.org/uploads/files/ceca\%20c-a\%20report\%20101210.pdf. Ac

Dubler, N. N., M. P. Webber, D. M. Swiderski, and the Faculty and the National Working Group for the Clinical Ethics Credentialing Project. 2009. Charting the future. Hastings Center Report 39(6): 29-33

Dubler, N., and C. Liebman. 2011. Bioethics Mediation: A Guide to Shaping Shared Solutions Nashville, TN: Vanderbilt University Press.

Fiester, A. 2007. The Failure of the Consult Model: Why "Mediation" Should Replace "Consultation." American Journal of Bioethics 7(2): 31-2.

Fiester, A. 2007. Mediation and Aporia. Journal of Clinical Ethics 18(4): 355-356.

Fiester, A. 2011. Ill-Placed Democracy: Ethics Consultations and the Moral Status of Voting. Journal of Clinical Ethics 22(4): 23-32. 


\section{PLEASE DO NOT CITE WITHOUT PERMISSION OF THE AUTHOR}

Fox, E., S. Myers, and R. A. Pearlman. 2007. Ethics consultation in United States hospitals: A national survey. American Journal of Bioethics 7(2): 13-25.

Gerrard, T.J., and J.D. Riddell. 1988. Difficult patients: black holes and secrets. British Medical Journal 297: 530-532.

Haas, L., J. Leiser, M. Magill, and O. Sanyer. 2005. Management of the Difficult Patient. American Family Physician 10: 2063-2068.

Hahn, S. 2001. Physical symptoms and physician-experienced difficulty in the physician-patient relationship. Annals of Internal Medicine 134: 897-904.

Hahn, S.R., K. Kroenke, R. L. Spitzer, D. Brody, J. B. Williams, M. Linzer, et al. 1996. The difficult patient: prevalence, psychopathology, and functional impairment. Journal of General Internal Medicine 11: 1-8.

Hahn, S.R., K.S. Thompson, T.A. Wills, V. Tern, and N. S. Budner. 1994. The difficult doctorpatient relationship: somatization, personality and psychopathology. Journal of Clinical Epidemiology 47: 647-657.

Jackson, J. L., and K. Kroenke. 1999. Difficult patient encounters in the ambulatory clinic: clinical predictors and outcomes. Archives of Internal Medicine 159: 1069-1075.

Kahn, M. 2009. What would Osler do? Learning from "difficult" patients. New England Journal of Medicine 361 (5): 442-3.

Knesper, D. 2007. My favorite tips for engaging the difficult patient on consultation-liaison psychiatry services. Psychiatric Clinics of North America 30: 245-252.

Lin, E. H., W. Katon, M. Von Korff, T. Bush, P. Lipscom, and J. Russo. 1991. Frustrating patients: physician and patient perspectives among distressed high users of medical services. Journal of General Internal Medicine 6: 241-6.

Miksanek, T. 2008. On caring for "difficult" patients. Health Affairs 27: 1422-1428.

Steinmetz, D., and H. Tabenkin. 2001. The 'difficult patient' as perceived by family physicians. Family Practice 18: 495-500.

Stone, D., B. Patton, and S. Heen. 1999. Difficult conversations: how to discuss what matters most. New York: Penguin Books.

Wasan A. D., J. Wootton, and R. N. Jamison. 2005. Dealing with difficult patients in your pain practice. Regional Anesthesia and Pain Medicine 30: 184-192. 
Autumn Fiester, PhD

Department of Medical Ethics and Health Policy

Perelman School of Medician at the University of Pennsylvania

PLEASE DO NOT CITE WITHOUT PERMISSION OF THE AUTHOR 